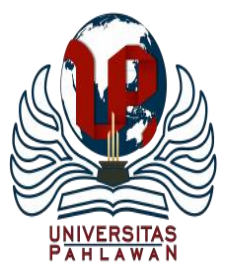

Edukatif : Jurnal Ilmu Pendidikan Volume 3 Nomor 4 Tahun 2021 Halm 1690 - 1698

EDUKATIF: JURNAL ILMU PENDIDIKAN

Research \& Learning in Education

https://edukatif.org/index.php/edukatif/index

\title{
Pengaruh Pola Pembinaan dan Pengawasan Kepala Sekolah terhadap Disiplin dan Kinerja Guru
}

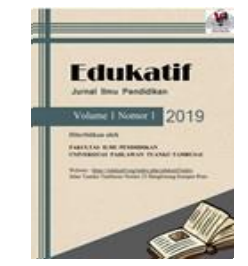

\author{
Desi Marlina \\ Universitas Jambi, Indonesia \\ E-mail : desimarlina0975@gmail.com
}

\begin{abstract}
Abstrak
Penelitian bertujuan untuk mengetahui pengaruh pola pembinaan kepala sekolah, pengawasan kepala sekolah, disiplin dan kinerja guru SMA Negeri Kabupaten Muaro Jambi. Jenis penelitian adalah kuantitatif. Populasi berjumlah 328 guru sedangkan sampel berjumlah 180 guru. Prosedur pengumpulan data berupa angket dengan menggunakan teknik analisa deskriptif melalui bantuan aplikasi SPSS. Hasil penelitian menunjukkan terdapat pengaruh pola pembinaan kepala sekolah terhadap disiplin guru, tidak terdapat pengaruh pola pengawasan kepala sekolah terhadap disiplin guru, tidak terdapat pengaruh pola pembinaan kepala sekolah terhadap kinerja guru, tidak terdapat pengaruh pola pengawasan kepala sekolah terhadap kinerja guru, terdapat pengaruh disiplin terhadap kinerja guru, terdapat pengaruh secara simultan pola pembinaan dan pola pengawasan kepala sekolah terhadap disiplin guru dilihat dari nilai f-hitung sebesar 3.805 dengan probabilitas sig $0,033<\alpha(0,05)$, dan tidak terdapat pengaruh secara simultan pola pembinaan dan pola pengawasan kepala sekolah terhadap kinerja guru dilihat dari nilai f-hitung sebesar 1.187 dengan probabilitas sig 0,318 $>\alpha(0,05)$.

Kata Kunci: Pola Pembinaan Kepala Sekolah, Pengawasan Kepala Sekolah, Disiplin Kerja, Kinerja.
\end{abstract}

\begin{abstract}
The purpose of the study was to determine the effect of the pattern of coaching the principal, supervision of the principal, discipline and teacher performance at the Muaro Jambi Regency Senior High School. The type of research is quantitative. The population is 328 teachers while the sample is 180 teachers. The data collection procedure is in the form of a questionnaire using descriptive analysis techniques through the help of the SPSS application. The results showed that there was an influence of the pattern of principal's coaching on teacher discipline, there was no influence of the pattern of principal's supervision on teacher's discipline, there was no influence of the pattern of principal's coaching on teacher performance, there was no influence of the pattern of principal's supervision on teacher performance, there was an influence of discipline on teacher performance. teacher performance, there is a simultaneous influence of the pattern of guidance and supervision of the principal on the discipline of the teacher seen from the f-count value of 3.805 with a probability of sig $0.033<(0.05)$, and there is no simultaneous effect of the pattern of guidance and supervision of the principal on teacher performance seen from the $f$-count value of 1.187 with a probability of sig $0.318>(0.05)$.
\end{abstract}

Keywords: Principal's Guidance Pattern, Principal Supervision, Work Discipline, Performance.

Copyright (c) 2021 Desi Marlina

$\triangle$ Corresponding author

Email : desimarlina0975@gmail.com

DOI : https://doi.org/10.31004/edukatif.v3i4.671

ISSN 2656-8063 (Media Cetak)

ISSN 2656-8071 (Media Online)

Edukatif : Jurnal Ilmu Pendidikan Vol 3 No 4 Tahun 2021 p-ISSN 2656-8063 e-ISSN 2656-8071 
1691 Pengaruh Pola Pembinaan dan Pengawasan Kepala Sekolah terhadap Disiplin dan Kinerja Guru - Desi Marlina

DOI: https://doi.org/10.31004/edukatif.v3i4.671

\section{PENDAHULUAN}

Menurut Sanjaya (Qolb \& Hamami, 2021) pendidikan pada dasarnya memiliki cakupan makna yang luas, merujuk kbbi.kemdikbud.go.id pendidikan berupa proses sikap tata laku permanusiaan atau kelompok yang dirubah dengan usaha pengajaran dan pelatihan. Pendidikan juga merupakan usaha sadar yang terencana untuk menciptakan suasana belajar yang menarik dengan proses pembelajaran yang baik agar peserta didik dapat mengembangkan potensi dirinya serta memiliki kekuatan spiritual keagamaan, pengendalian diri, kepribadian, kecerdasan, akhlak mulia, serta keterampilan yang diperlukan bagi dirinya, masyarakat, bangsa dan negara. Pentingnya sumber daya manusia, menuntut setiap lembaga pendidikan untuk mendapatkan SDM yang berkualitas dan produktif. Maka dari itu perlu manajemen pengembangan SDM dalam lembaga pendidikan di kelola dengan sebaiknya. (Mulyani \& Jamilus, 2021). Menurut Woldopo (Mulyani \& Jamilus, 2021) Pendidik (guru) adalah komponen SDM yang harus dikembangkan kompetensinya secara berkesinambungan. Pendidikan merupakan usaha sadar dan terencana yang dilakukan seseorang dalam menyelenggarakan kegiatan pengembangan diri peserta didik agar menjadi manusia paripurna yang sesuai dengan harapan dan tujuan yang telah ditentukan,dan mewujudkan suasana belajar dan proses pembelajaran agar peserta didik secara aktif mengembangkan potensi-potensi yang ada pada dirinya (Komprit, 2015).

Kinerja adalah hasil atau tingkat keberhasilan seseorang secara keseluruhan selama periode tertentu dalam melaksanakan tugas dibandingkan dengan berbagai kemungkinan, seperti standar hasil kerja, target atau sasaran, atau kriteria yang telah ditentukan terlebih dahulu dan telah disepakati bersama (Rivai, 2005). Menurut (Pasolong, 2010) konsep kinerja pada dasarnya dapat dilihat dari dua segi, yaitu kinerja pegawai (individu) dan kinerja organisasi. Menurut Soegeng, P (Amran, 2013) yang menjelaskan bahwa yang dimaksud dengan disiplin adalah disiplin sebagai kondisi yang tercipta dan terbentuk melalui proses dari serangkaian perilaku yang menunjukan nilai-nilai ketaatan, kepatuhan, kesetiaan, keteraturan dan ketertiban.

Masih cukup rendahnya kinerja guru SMA Negeri Kabupaten Muaro Jambi juga terlihat dari proses perencanaan program pembelajaran khususnya dalam kegiatan perancangan RPP yang masih belum maksimal dilakukan oleh masing-masing individu guru secara mandiri, dan RPP yang digunakan dalam kegiatan pembelajaran selama ini biasanya hasil rancangan bersama pada kegiatan Musyawarah Guru Mata Pelajaran (MGMP) sehingga RPP ini dinilai belum kontekstual. Rendahnya kinerja guru di kabupeten Muaro Jambi, hal ini dapat terlihat dari kemampuan dan profesionalisme guru yang masih rendah seperti dalam kegiatan belajar mengajar. Salah satu contohnya masih ada beberapa guru yang mengajar tidak sesuai bidangnya.

Kegiatan penelitian ini dibatasi untuk dapat menghindari adanya penyimpangan atau pelebaran pokok masalah agar penelitian yang akan dilakukan ini lebih terarah dan memudahkan peneliti dalam pembahasannya sehingga tujuan dari penelitian ini dapat tercapai. Beberapa batasan masalah dalam penelitian yaitu lingkup penelitian hanya untuk mengetahui pengaruh pola pembinaan dan pengawasan kepala sekolah terhadap disiplin dan kinerja guru, informasi yang disajikan yaitu pola pembinaan kepala sekolah, pola pengawasan kepala sekolah, gambaran disiplin guru, gambaran kinerja guru. Dalam kegiatan penelitian ini penulis melakukan kajian pustaka terhadap berbagai penelitian yang pernah dilakukan sebelumnya yang berkaitan dengan permasalahan yang sama. Dari hasil kajian tersebut, maka penulis mendapatkan berberapa sumber yang pokok permasalahannya hampir sama dengan yang akan dilakukan oleh penulis, yaitu penelitian yang dilakukan oleh (Alwi, 2010) tentang Pola Pembinaan dan Pengawasan Kepala Sekolah dalam. Meningkatkan Disiplin dan Kinerja Guru SMP Negeri Sekecamatan Ketungau Hulu Kabupaten Sintang.

Persamaan penelitian yang akan dilakukan ini dengan penelitian yang telah dilakukan sebelumnya adalah pada komponen-komponen yang akan diteliti yaitu pola pembinaan, pola pengawasan, disiplin dan kinerja guru. Sedangkan perbedaan penelitian yang akan dilakukan dengan penelitian yang telah dilakukan ini adalah pertama pada tingkatan sekolahnya. Penelitian terdahulu dilakukan pada tingkatan sekolah menengah pertama, sedangkan penelitian yang akan dilakukan ini pada tingkatan sekolah menengah atas, dengan asumsi 


\section{Pengaruh Pola Pembinaan dan Pengawasan Kepala Sekolah terhadap Disiplin dan Kinerja Guru - Desi}

Marlina

DOI: https://doi.org/10.31004/edukatif.v3i4.671

bahwa bentuk pola pengawasan dan pola pembinaan kepala sekolah pada tingkatan SMP dapat berbeda dengan pola pembinaan dan pengawasan kepala sekolah pada tingkatan SMA dengan alasan bahwa psikologi dari guru yang dibina dan diawasi dapat jadi berbeda antara guru pada tingkatan SMP dengan guru pada tingkatan SMA, sehingga Kepala Sekolah masing masing jenjang pendidikan mempunyai strategi dan model pola kepemimpinan yang dapat jadi berbeda karena permasalahan yang dihadapi bisa jadi berbeda juga.

Perbedaan selanjutnya adalah pada indikator disiplin dan indikator kinerja yang menjadi ukuran dalam penelitian ini. Dalam penelitian terdahulu yang menjadi indikator disiplin adalah disiplin diri dan disiplin kelompok, sedangkan dalam penelitian yang akan dilakukan ini indikator disiplin secara keseluruhan yang berkaitan dengan kerja dan hubungannya dengan tata tertib yang ada. Selanjutnya, dalam penelitian sebelumnya yang menjadi indikator kinerja adalah kemampuan teknis, kemampuan konseptual, dan kemampuan hubungan interpersonal, sedangkan dalam penelitian yang akan dilakukan ini yang menjadi indikator kinerja adalah indikator kinerja guru yang sudah baku yang diterbitkan (Depdiknas, 2008).

Selanjutnya peneliti melakukan kajian terhadap hasil penelitian (Rizal, 2019) "Pengaruh Motivasi Kerja dan Kedisiplinan terhadap Kinerja Guru SMP”. Persamaan penelitian ini dengan penelitian yang akan dilakukan adalah pada variabel disiplin dan kinerja yang akan dilihat pengaruhnya. Sedangkan perbedaan penelitian ini dengan penelitian yang akan dilakukan adalah variabel yang memberi pengaruh terhadap disiplin dan kinerja tersebut, pada penelitian ini yang memberi pengaruh adalah motivasi kerja, sedangkan pada penelitian yang akan dilakukan variabel yang akan memberi pengaruh ada dua yaitu pola pembinaan dan pola pengawasan kepala sekolah.

Kajian berikutnya terhadap hasil penelitian (Siska, 2017) Pengaruh Disiplin dan Motivasi Kerja terhadap Kinerja Guru pada SMAN 1 Canduang Kabupaten Agam. Persamaan penelitian ini dengan penelitian yang akan dilakukan adalah pada variable terikat yang akan diteliti yaitu kinerja. Persamaan lainnya adalah pada tingkatan sekolah yaitu Sekolah Menengah Atas (SMA) Negeri. Artinya bahwa karakteristik sampel dapat dipastikan hampir sama. Perbedaan penelitian yang akan dilakukan ini dengan penelitian Adilla Juita Siska adalah pada variable bebasnya. Adilla Juita Siska menggunakan disiplin dan motivasi kerja sebagai variable bebas sedangkan peneliti menggunakan pola pembinaan dan pengawasan kepala sekolah sebagai variable bebas dalam penelitian ini.

Selanjutnya, peneliti melakukan kajian terhadap hasil penelitian oleh (Sopaheluakan, 2020) tentang hubungan antara kepemimpinan kepala sekolah dan budaya kerja dan kinerja guru SMA Negeri 1 Seram Barat Kabupaten Seram bagian Barat. Persamaan penelitian ini adalah pada aspek yang akan diukur yaitu kinerja guru SMA. Sedangkan perbedaan penelitian ini adalah pada aspek kepemimpinan dan budaya kerja yang tidak menjadi kajian dan pengukuran dalam penelitian yang akan peneliti lakukan. Kajian berikutnya, yaitu kajian terhadap hasil penelitian oleh Suyono.

Adapun tesis (Suyono, Peran Kepala Madrasah dalam Meningkatkan Kinerja Guru (Studi Kasus di Madrasah Tsanawiyah Negeri Tumapang Kabupaten Malang), 2014) Persamaan penelitian ini dengan penelitian yang akan dilakukan yaitu pada variabel kinerja yang diukur, sedangkan perbedaan penelitian ini dengan penelitian yang akan dilakukan adalah pada variabel bebasnya yaitu pada penelitian ini variabel bebasnya adalah peran kepala madrasah, sedangkan pada penelitian yang akan dilakukan variabel bebasnya adalah pola pembinaan dan pengawasan Kepala Sekolah.

\section{METODE PENELITIAN}

Penelitian ini menggunakan jenis penelitian kuantitatif. Menurut (Creswel \& Clark, 2011) menjelaskan penelitian kuantitatif mewajibkan seorang peneliti untuk menjelaskan bagaimana suatu variabel mempengaruhi variabel yang lainnya. Pada penelitian ini yang menjadi populasi adalah guru SMA Negeri Kabupaten Muaro Jambi. Menurut (Arikunto, 2013) Populasi adalah keseluruhan objek penelitian. Apabila 
1693 Pengaruh Pola Pembinaan dan Pengawasan Kepala Sekolah terhadap Disiplin dan Kinerja Guru - Desi Marlina

DOI: https://doi.org/10.31004/edukatif.v3i4.671

seseorang ingin meneliti sebuah elemen yang ada dalam wilayah penelitian tersebut, maka penelitiannya merupakan penelitian populasi. Berdasarkan data pada tahun ajaran 2020/2021 jumlah guru dari kesepuluh sekolah yang ada di Kabupaten Muaro Jambi sebanyak 328 orang. Pengumpulan data dalam penelitian ini menggunakan instrumen berbentuk kuesioner/angket. Adapun menurut (Sugiyono, 2009) Kuesioner atau angket adalah suatu teknik pengumpulan informasi yang memungkinkan analis mempelajari sikap-sikap, keyakinan, perilaku, dan karakteristik beberapa orang utama di dalam organisasi yang bisa terpengaruh oleh sistem yang diajukan atau oleh sistem yang sudah ada. Pengembangan instrumen untuk setiap variabel disajikan mulai dari definisi konseptual, definisi operasional, kisi-kisi instrumen, jenis instrument serta validitas dan penghitungan reliabilitas instrument. Adapun variabel dalam penelitian ini dapat dilihat pada gambar diwabah ini

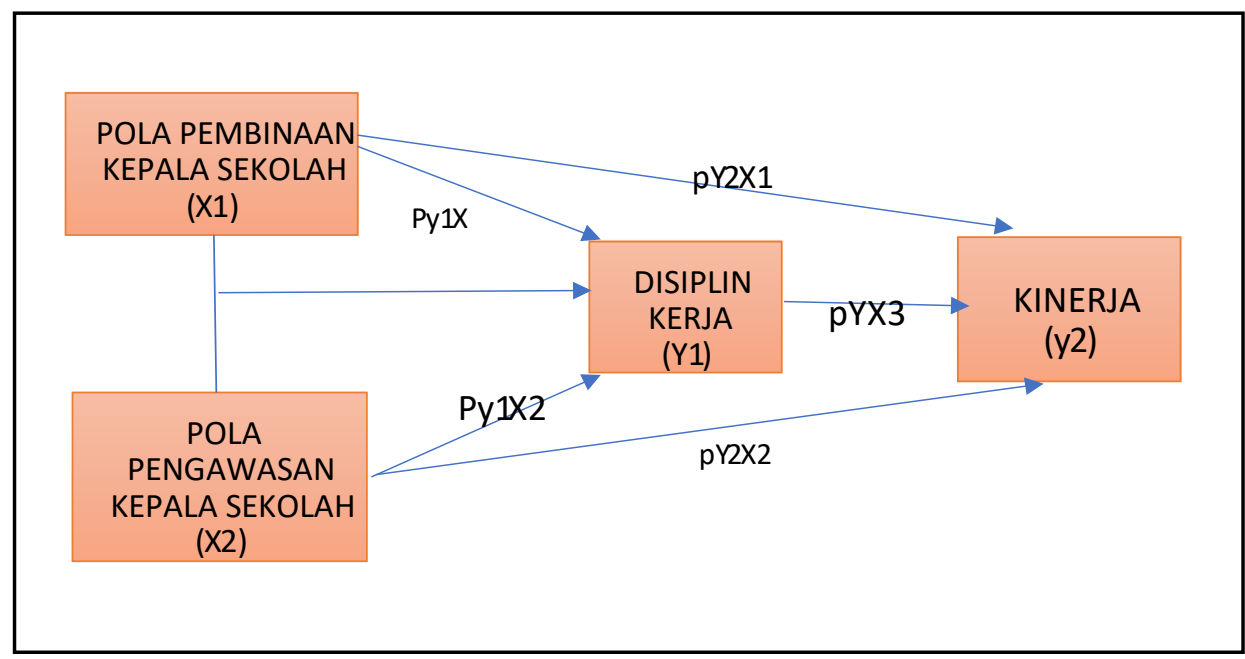

Gambar 1. Kerangka Pemikiran

\section{HASIL DAN PEMBAHASAN PENELITIAN}

Untuk mengetahui variabel yang berpengaruh signifikan secara parsial dilakukan pengujian koefisien regresi dengan menggunakan statistik Uji T. Penentuan hasil pengujian (penerimaan/penolakan hipotesis satu $\left(H_{1}\right)$ dapat dilakukan dengan membandingkan t-hitung dengan t-tabel atau juga dapat dilihat dari nilai signifikannya. Hasil pengujian hipotesisi secara parsial dengan menggunakan SPSS adalah sebagai berikut:

Tabel 1. Hasil Uji Hipotesis Parsial Pola Pembinaan Kepala Sekolah terhadap Disiplin Kerja Guru

\begin{tabular}{llll}
\hline No & Model & t-hitung & Probabilitas Sig \\
\hline & Predictor (Constant) Pola Pembinaan Kepala & 2.775 & 0.009 \\
& Sekolah & \\
& Variabel Dependen: Disiplin Kerja Guru & \\
\end{tabular}

Berdasarkan output didapatkan nilai t-hitung sebesar 2.775 dengan probabilitas sig $0,009<\alpha(0,05)$ atau $t_{\text {hitung }}>\mathrm{t}_{\text {tabel }}$ yaitu 2.775>2.035. hal tersebut berarti bahwa terdapat pengaruh pola pembinaan kepala sekolah terhadap disiplin kerja guru. Untuk melihat persentase besarnya pengaruh parsial variable pola pembinaan kepala sekolah terhadap disiplin kerja guru, yaitu dengan melihat model summary.

Tabel 2 Output Model Summary Pola Pembinaan Kepala Sekolah terhadap Disiplin Kerja Guru

\begin{tabular}{lll}
\hline No & Model & R Square \\
\hline $\begin{array}{l}\text { Predictors (Constant) Pola Pembinaan Kepala Sekolah } \\
\text { Variabel Dependen: Disiplin Kerja Guru }\end{array}$ & 0.189 \\
\hline
\end{tabular}


1694 Pengaruh Pola Pembinaan dan Pengawasan Kepala Sekolah terhadap Disiplin dan Kinerja Guru - Desi Marlina

DOI: https://doi.org/10.31004/edukatif.v3i4.671

Pada table ini nilai $R$ Square bernilai 0,189 yang artinya pola pembinaan kepala sekolah memberikan pengaruh terhadap disiplin kerja guru sebesar $18,9 \%$ dan sisanya dipengaruhi variable lain.

Table 3 Uji Hipotesis Parsial Pola Pengawasan Kepala Sekolah terhadap Disiplin Kerja Guru

\begin{tabular}{llll}
\hline No & Model & t-hitung & Probabilitas Sig \\
\hline & $\begin{array}{l}\text { Predictor (Constant) Pola Pengawasan Kepala Sekolah } \\
\text { Variabel Dependen: Disiplin Kerja }\end{array}$ & 1.144 & 0.261 \\
\hline
\end{tabular}

Berdasarkan output didapatkan nilai t-hitung sebesar 1.144 dengan probabilitas sig $0,261>\alpha(0,05)$ atau $t_{\text {hitung }}>t_{\text {tabel }}$ yaitu $1.144<2.035$. hal tersebut berarti bahwa tidak terdapat pengaruh pola pengawasan kepala sekolah terhadap disiplin kerja guru SMA Negeri Kabupaten Muaro Jambi. Untuk melihat persentase besarnya pengaruh parsial variable pola pengawasan Kepala Sekolah terhadap disiplin kerja guru, yaitu dengan melihat model summary.

Table 4 Output Model Summary Pola Pengawasan Kepala Sekolah terhadap disiplin kerja guru

\begin{tabular}{lll}
\hline No & \multicolumn{1}{c}{ Model } & R Square \\
\hline & Predictors (Constant) Pola Pembinaan Kepala Sekolah & 0.038 \\
Variabel Dependen: Disiplin Kerja Guru & \\
\hline
\end{tabular}

Pada table ini nilai $R$ Square bernilai 0,038 yang artinya pola pengawasan kepala sekolah hanya memberikan pengaruh terhadap disiplin kerja guru sebesar 3,8\% dan sisanya dipengaruhi variable lain. Dikarenakan pengaruh yang diberikan sangat kecil, maka dapat dikatakan bahwa pola pengawasan kepala sekolah tidak memberikan pengaruh terhadap disiplin kerja guru SMA Negeri Kabupaten Muaro Jambi. Hasil ini berbeda dengan hasil penelitian yang telah dilakukan oleh (Alwi, 2010) yang menjelaskan bahwa pola pengawasan kepala sekolah memberikan pengaruh terhadap disiplin guru.

Tabel 5 Uji Hipotesis Parsial X1 terhadap Y2

\begin{tabular}{llll}
\hline No & Model & t-hitung & Probabilitas Sig \\
\hline & Predictor (Constant) Pola Pembinaan Kepala & 1.563 & 0.128 \\
& Sekolah & & \\
& Variabel Dependen: Kinerja & & \\
\hline
\end{tabular}

Berdasarkan output didapatkan nilai t-hitung sebesar 1.563 dengan probabilitas sig $0,128>\alpha(0,05)$ atau $t_{\text {hitung }}>t_{\text {tabel }}$ yaitu $1.563<2.035$. hal tersebut berarti bahwa tidak terdapat pengaruh pola pembinaan kepala sekolah terhadap kinerja kerja guru SMA Negeri Kabupaten Muaro Jambi. Untuk melihat persentase besarnya pengaruh parsial variabel pola pembinaan kepala sekolah terhadap kinerja guru, yaitu dengan melihat model summary. Hasil penelitian ini berbeda dengan penelitian yang telah dilakukan oleh (Alwi, 2010) dimana didalam tesis yang ditulisnya menyatakan bahwa pola pembinaan kepala sekolah mempengaruhi kinerja guru.

Table 6 Output Model Summary X1 terhadap Y2

\begin{tabular}{lll}
\hline No & Model & R Square \\
\hline & Predictors (Constant) Pola Pembinaan Kepala Sekolah & 0.069 \\
& Variabel Dependen: Kinerja Guru & \\
\hline
\end{tabular}

Dari table ini nilai R Square adalah 0,069 yang artinya bahwa pengaruh pola pembinaan kepala sekolah terhadap kinerja guru hanya sebesar 6,9\% dimana angka ini dianggap terlalu kecil sehingga pola pembinaan kepala sekolah dikatakan tidak mempengaruhi kinerja guru SMA Negeri kabupaten Muaro Jambi. 
1695 Pengaruh Pola Pembinaan dan Pengawasan Kepala Sekolah terhadap Disiplin dan Kinerja Guru - Desi Marlina

DOI: https://doi.org/10.31004/edukatif.v3i4.671

Table 7 Uji Hipoteis parsial X2 terhadap Y2

\begin{tabular}{llll}
\hline No & Model & t-hitung & Probabilitas Sig \\
\hline & Predictor (Constant) Pola Pembinaan Kepala & 1.563 & 0.128 \\
& Sekolah & & \\
& Variabel Dependen: Kinerja & \\
\hline
\end{tabular}

Berdasarkan output didapatkan nilai t-hitung sebesar 0,440 dengan probabilitas sig 0,663> $>(0,05)$ atau $t_{\text {hitung }}<\mathrm{t}_{\text {tabel }}$ yaitu $0,440<2.035$. hal tersebut berarti bahwa tidak terdapat pengaruh pola pengawasan kepala sekolah terhadap kinerja kerja guru SMA Negeri Kabupaten Muaro Jambi. Untuk melihat persentase besarnya pengaruh parsial variable pola pengawasan kepala sekolah terhadap kinerja guru, yaitu dengan melihat model summary.

Table 8 Output Model Summary X2 terhadap Y2

\begin{tabular}{lll}
\hline No & Model & R Square \\
\hline & Predictors (Constant) Pola Pengawasan Kepala Sekolah & 0.006 \\
& Variabel Dependen: Kinerja Guru \\
\hline
\end{tabular}

Dari table 4.8 diketahui nilai $\mathrm{R}$ Square 0,006 dimana dapat dikatan bahwa pola pengawasan kepala sekolah hanya memberikan pengaruh kepada kinerja guru sebesar $0,6 \%$ dan ini dinilai merupakan pengaruh yang sangat kecil sehingga dapat dikatakan bahwa pola pengawasan kepala sekolah tidak memberikan pengaruh terhadap kinerja guru SMA Negeri Kabupaten Muaro Jambi. Hal ini berbeda dengan hasil penelitian yang dilakukan (Alwi, 2010) yang menyatakan terdapat pengaruh pola pengawasan kepala sekolah terhadap kinerja guru.

Table 9 Uji Hipotesis parsial Y1 terhadap Y2

\begin{tabular}{llll}
\hline No & Model & t-hitung & Probabilitas Sig \\
\hline & Predictor (Constant) Disiplin Kerja & 3.896 & 0.000 \\
& Variabel Dependen: Kinerja Guru & & \\
\hline
\end{tabular}

Berdasarkan output didapatkan nilai t-hitung sebesar 3.896 dengan probabilitas sig $0,000<\alpha(0,05)$ atau $t_{\text {hitung }}>\mathrm{t}_{\text {tabel }}$ yaitu 3.896>2.035. Hal tersebut berarti bahwa terdapat pengaruh disiplin kerja guru terhadap kinerja kerja guru SMA Negeri Kabupaten Muaro Jambi. Untuk melihat persentase besarnya pengaruh parsial variable disiplin guru terhadap kinerja guru, yaitu dengan melihat model summary di bawah ini:

Tabel 10 Output Model Summary Y1 terhadap Y2

\begin{tabular}{lll}
\hline No & Model & R Square \\
\hline & Predictors (Constant) Disiplin Kerja & 0.315 \\
& Variabel Dependen: Kinerja Guru & \\
\hline
\end{tabular}

Berdasarkan table 4.10 didapatkan nilai R Square sebesar 0,315 yang artiya bahwa disiplin kerja guru memberikan pengaruh sebesar 31,5\% terhadap kinerja guru sedangkan sisanya dipengaruhi variable lain. Hal ini sejalan dengan penelitian yang telah dilakukan oleh (Siska, 2017) yang menjelaskan bahwa disiplin kerja mempengaruhi kinerja guru secara signifikan.

Table 11 Uji Hipotesis simultan X1,X2 terhadap Y1

\begin{tabular}{llll}
\hline No & Model & t-hitung & Probabilitas Sig \\
\hline & $\begin{array}{l}\text { Predictor (Constant) pola pembinaan dan } \\
\text { pola pengawasan Kepala Sekolah }\end{array}$ & 3.805 & 0.033 \\
$\quad$ Variabel Dependen: disiplin kerja & & \\
\hline
\end{tabular}


1696 Pengaruh Pola Pembinaan dan Pengawasan Kepala Sekolah terhadap Disiplin dan Kinerja Guru - Desi Marlina

DOI: https://doi.org/10.31004/edukatif.v3i4.671

Berdasarkan output didapatkan nilai f-hitung sebesar 3.805 dengan probabilitas sig $0,033<\alpha(0,05)$ atau $\mathrm{f}_{\text {hitung }}>\mathrm{f}_{\text {tabel }}$ yaitu 3.805>3,32 hal tersebut berarti bahwa terdapat pengaruh secara simultan pola pembinaan dan pola pengawasan kepala sekolah terhadap disiplin kerja guru SMA Negeri Kabupaten Muaro Jambi. Hal ini sejalan dengan penelitian yang dilakukan (Alwi, 2010) yang menjelaskan bahwa secara simultan pola pembinaan dan pola pengawasan Kepala Sekolah akan mempengaruhi disiplin guru.

Table 12 Uji Hipotesis (Uji F Simultan X1,X2 terhadap Y2)

\begin{tabular}{lll}
\hline No & Model & R Square \\
\hline & Predictors (Constant) Kinerja Guru & 1.187 \\
& Variabel Dependen: pola pembinaan & \\
dan pola pengawasan Kepala Sekolah & \\
\hline
\end{tabular}

Berdasarkan output didapatkan nilai f-hitung sebesar 1.187 dengan probabilitas sig $0,318>\alpha(0,05)$ atau $\mathrm{f}_{\text {hitung }}<\mathrm{f}_{\text {tabel }}$ yaitu $1.187<3.32$ hal tersebut berarti bahwa tidak terdapat pengaruh secara simultan pola pembinaan dan pola pengawasan kepala sekolah terhadap kinerja guru SMA Negeri Kabupaten Muaro Jambi.

Table 13 Ouput Model Summary pengaruh simultan X1 dan X2 terhadap Y

\begin{tabular}{llll}
\hline No & Model & t-hitung & Probabilitas Sig \\
\hline & $\begin{array}{l}\text { Predictor (Constant) pola pembinaan } \\
\text { dan pola pengawasan Kepala Sekolah }\end{array}$ & 3.805 & 0.033 \\
& Variabel Dependen: disiplin kerja & & \\
\hline
\end{tabular}

Berdasarkan table output model summary di atas, diketahui nilai koefisien determinan atau R Square adalah sebesar 0,192. Nilai R Square 0,192 ini berasal dari pengkuadratan nilai koefisien korelasi atau R, yaitu $0,438 \times 0,438=0,192$. Hasil perhitungan $\mathrm{R}$ Square tersebut mengandung arti bahwa variable pola pembinaan Kepala Sekolah (X1) dan variable pola pengawasan Kepala Sekolah (X2) secara simultan (Bersama-sama) berpengaruh terhadap variable disiplin kerja guru (Y1) sebesar 19,2\% sedangkan sisanya (100\%$19,2 \%=80,8 \%$ ) dipengaruhi oleh variable lain diluar persamaan regresi ini atau variable yang tidak diteliti.

Tabel 14 Output Model Summary pengaruh simultan X1 dan X2 terhadap Y2

\begin{tabular}{lll}
\hline No & Model & R Square \\
\hline & Predictors (Constant) pola pembinaan dan & 0.069 \\
& pola pengawasan Kepala Sekolah Variabel & \\
& Dependen: Kinerja Guru &
\end{tabular}

Berdasarkan output model summary ini didapatkan nilai R Square 0,069 yang artinya bahwa variable pola pembinaan kepala sekolah (X1) dan variable pola pengawasan kepala sekolah (X2) secara simultan (Bersama-sama) tidak berpengaruh kepada variable kinerja (Y2). Hal ini tidak sejalan dengan penelitian yang dilakukan (Alwi, 2010) yang menjelaskan bahwa secara simultan pola pembinaan dan pengawasan kepala sekolah secara signifikan mempengaruhi kinerja guru.

Keterbatasan temuan kegiatan penelitian ini dibatasi untuk dapat menghindari adanya penyimpangan atau pelebaran pokok masalah agar penelitian yang akan dilakukan ini lebih terarah dan memudahkan peneliti dalam pembahasannya sehingga tujuan dari penelitian ini dapat tercapai. Beberapa batasan masalah dalam penelitian ini yaitu lingkup penelitian hanya untuk mengetahui pengaruh pola pembinaan dan pengawasan 
1697 Pengaruh Pola Pembinaan dan Pengawasan Kepala Sekolah terhadap Disiplin dan Kinerja Guru - Desi Marlina

DOI: https://doi.org/10.31004/edukatif.v3i4.671

kepala sekolah terhadap disiplin dan kinerja guru, informasi yang disajikan yaitu pola pembinaan kepala sekolah, pola pengawasan kepala sekolah, gambaran disiplin guru dan gambaran kinerja guru.

Manfaat penelitian bagi ilmu pendidikan yaitu penelitian ini diharapkan bermanfaat bagi pengembangan ilmu kependidikan terutama dalam pola pengawasan dan pola pembinaan yang efektif dalam meningkatkan disiplin dan kinerja guru. Hasil penelitian ini diharapkan menjadi referensi bagi peneliti lainnya dalam melakukan penelitian yang berkaitan dengan pengawasan dan pembinaan bagi guru. Hasil penelitian ini menjadi masukan bagi semua pihak terutama bagi kepala sekolah dalam mengembangkan pola pembinaan dan pengawasan kepala sekolah. Hasil penelitian ini menjadi masukan bagi kepala sekolah dalam upaya meningkatkan disiplin dan kinerja guru.

\section{KESIMPULAN}

Berdasarkan analisis hasil penelitian dan pembahasan mengenai pengaruh pola pembinaan dan pola pengawasan kepala sekolah terhadap disiplin dan kinerja guru SMA Negeri Kabupaten Muaro Jambi, maka didapatkan kesimpulan terdapat pengaruh pola pembinaan kepala sekolah terhadap disiplin guru, tidak terdapat pengaruh pola pengawasan kepala sekolah terhadap disiplin guru, tidak terdapat pengaruh pola pembinaan kepala sekolah terhadap kinerja guru, tidak terdapat pengaruh pola pengawasan kepala sekolah terhadap kinerja guru SMA Negeri kabupaten Muaro Jambi. terdapat pengaruh disiplin terhadap kinerja guru, terdapat pengaruh pola pembinaan dan pengawasan kepala sekolah terhadap disiplin guru, tidak terdapat pengaruh pola pembinaan dan pengawasan kepala sekolah terhadap kinerja guru.

\section{UCAPAN TERIMA KASIH}

Puji dan syukur penulis panjatkan kehadirat Allah SWT, karena berkat rahmat dan karunia-Nya peneliti dapat menyelesaikan Tesis yang berjudul "Pengaruh Pola Pembinaan dan Pola Pengawasan Kepala Sekolah terhadap Disiplin dan Kinerja Guru". Selama kegiatan penyusunan Tesis ini, penulis banyak mendapat bantuan, dukungan, dan masukan baik berupa ide ataupun saran dari berbagai pihak. Untuk itulah penulis mengucapkan terimakasih dan penghargaan yang setinggi-tingginya kepada Rektor Universitas Jambi Prof. Drs. H. Sutrisno, M. Sc., Ph. D, Direktur PascaSarjana Universitas Jambi Prof. Dr. H. Haryadi, SE, MMS, Ketua Program Studi Magister Manajemen Pendidikan, Dr. Dra. Hj. Muazza, M.Si, Bapak Prof. Amirul Mukminin, S. Pd. M. Sc. Ed., PhD., selaku Dosen pembimbing I dan Bapak Dr. K.A. Rahman, M. Pd. I., selaku Dosen pembimbing II, Seluruh TIM penguji, Dosen, dan Staf pengelola PascaSarjana Universitas Jambi yang telah banyak memberikan ilmu pengetahuan serta fasilitas belajar yang sangat peneliti butuhkan, Kepala Dinas Pendidikan Provinsi Jambi, Kepala Sekolah dan para Guru SMAN Kabupaten Muaro Jambi, Rekan-rekan seperjuangan di Program Studi Magister Manajemen Pendidikan yang bersama-sama menempuh studi dalam suka dan duka serta selalu memberikan motivasi yang luar biasa satu sama lain, Semua pihak yang tidak dapat penulis sebutkan satu persatu yang telah memberikan bantuan moril maupun materil dalam penyelesaian Tesis ini.

\section{DAFTAR PUSTAKA}

Alwi, A. F. (2010). Pola Pembinaan dan Pengawasan Kepala Sekolah dalam Meningkatkan Disiplin dan Kinerja Guru SMP Negeri Sekecamatan Ketungau Hulu Kabupaten Sintang.

Amran. (2013). Pengaruh Disiplin Kerja Terhadap Kinerja Pegawai Kantor. Departemen Sosial Kabupaten Gorontalo, Jurnal Ichsan Gorontalo, 4(2). 
1698 Pengaruh Pola Pembinaan dan Pengawasan Kepala Sekolah terhadap Disiplin dan Kinerja Guru - Desi Marlina

DOI: https://doi.org/10.31004/edukatif.v3i4.671

Arikunto, S. (2013). Prosedur Penelitian. Jakarta: Rineka Cipta.

Creswel, \& Clark. (2011). Designing and conducting mixed methods research. Sage publications.

Dantes, \& Nyoman. (2012). Metode Penelitian. Yogyakarta: Andi.

Depdiknas. (2008). Penilaian Kinerja Guru . Jakarta: Direktorat Tenaga Kependidikan. Dirjen PMPTK.

Khori. (2016). Manajemen strategik dan mutu pendidikan Islam. Manageria: Jurnal Manajemen Pendidikan Islam, 1(1), 75-99.

Komprit. (2015). i, Manajemen Pendidikan. Yogyakarta: Ar-Ruzza Media.

Mulyani, \& Jamilus. (2021). Pengembangan Pendidik Sebagai Sumber Daya Manusia di Sekolah Menengah Atas. EDUKATIF: JURNAL ILMU PENDIDIKAN, $3(4), \quad 1170 \quad$ - 1176 doi:https://edukatif.org/index.php/edukatif/index

Pasolong, H. (2010). Teori Administrasi Publik. Bandung: Alfabeta.

Qolb, S. K., \& Hamami, T. (2021, Universitas Pahlawan tuanku Tambusai Riau). Impelementasi Asas-asas Pengembangan Kurikulum terhadap Pengembangan KurikulumPendidikan Agama Islam. EDUKATIF: JURNAL ILMU PENDIDIKAN, 3(4), 1120 - 1132. doi:https://edukatif.org/index.php/edukatif/index

Rivai. (2005). Manajemen Sumber daya Manusia untuk Perusahaan: dari Teori ke Praktik. Jakarta: PT.Raja Grafindo Persada.

Rizal, A. S. (2019). Pengaruh Motivasi Kerja dan Kedisiplinan terhadap Kinerja Guru SMP. Ulul Albab, 23, $15-22$.

Siska, A. J. (2017). Pengaruh Disiplin dan Motivasi Kerja terhadap Kinerja Guru pada SMAN 1 Canduang Kabupaten Agam. J.U.S.I.E, 1(2).

Sopaheluakan, N. (2020). Hubungan antara Kepemimpinan Kepala Sekolah dan Budaya Kerja dan Kinerja Guru SMA Negeri 1 Seram Barat Kabupaten Seram. E-jurnal UKI, 9(2).

Sormin. (2017). Manajemen Kepala Sekolah Dalam Meningkatkan Mutu Pendidikan Di Smp Muhammadiyah 29 Padang sidimpuan. Al-Muaddib: Jurnal Ilmu-Ilmu Sosial dan Keislaman, 2(1).

Sugiyono. (2009). Metode Penelitian Kuantitatif Kualitatif dan R\&D. Bandung: Alfabeta.

Suyitno. (2021). Peningkatan Daya Saing Madrasah Melalui Optimalisasi Program Ekstrakurikuler. EDUKATIF: JURNAL ILMU PENDIDIKAN, 3(4), 1161 - 1169.

Suyono. (2014). Peran Kepala Madrasah dalam Meningkatkan Kinerja Guru (Studi Kasus di Madrasah Tsanawiyah Negeri Tumapang Kabupaten Malang) .

Umayah. (2015). Upaya Guru dan Kepala Madrasah dalam Meningkatkan Daya Saing Madrasah. Jurnal Kajian Pendidikan Islam, 259-288. 